\title{
The impact of surgical excision of the primary tumor in stage IV breast cancer on survival: a meta-analysis
}

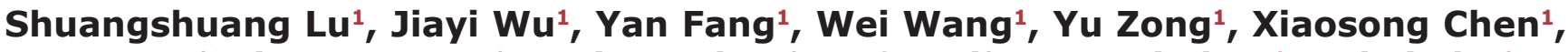 \\ Ou Huang ${ }^{1}$, Jian-Rong He ${ }^{1}$, Weiguo Chen ${ }^{1}$, Yafen Li ${ }^{1}$, Kunwei Shen ${ }^{1}$ and Li Zhu $^{1}$ \\ ${ }^{1}$ Comprehensive Breast Health Center, Ruijin Hospital, Shanghai Jiaotong University School of Medicine, Shanghai 200025, \\ P.R. China
}

Correspondence to: Li Zhu, email: zhuli8@yeah.net

Keywords: stage IV breast cancer; surgical excision; primary tumor; survival; meta-analysis

Received: March 01, 2017 Accepted: October 30, $2017 \quad$ Published: December 13, 2017

Copyright: Lu et al. This is an open-access article distributed under the terms of the Creative Commons Attribution License 3.0 (CC BY

3.0), which permits unrestricted use, distribution, and reproduction in any medium, provided the original author and source are credited.

\section{ABSTRACT}

Introduction: Approximately $5 \%$ of primary breast cancer patients present de novo stage IV breast cancer, for whom systematic therapy is the mainstream treatment. The role of surgical excision of the primary tumor has been controversial due to inconsistent results of relevant studies. Recently, with the reports of some relevant preclinical data, retrospective studies and randomized clinical trials, we've got more evidence to reexamine the issue. Based on those above, a literature review and meta-analysis was performed to determine whether surgery of the primary tumor could improve overall survival in the setting of stage IV breast cancer.

Materials and Methods: A comprehensive search of PubMed, OVID, American Society of Clinical Oncology (ASCO) symposium documents, European Society for Medical Oncology (ESMO) symposium documents and San Antonio Breast Cancer Symposium (SABCS) symposium documents was performed to identify published literature that evaluated survival benefits from excision of the primary tumor in the setting of stage IV breast cancer. Data were extracted in review of appropriate studies by the authors independently. The primary endpoint was overall survival following surgical removal of the primary tumor. Secondary endpoints were the impacts of surgery on progression free survival (PFS) and time to progression (TTP).

Results: Data from 19 retrospective studies showed a pooled hazard ratio of 0.65 (95\% confidence interval $(95 \% \mathrm{CI}), 0.60-0.71, P<0.01=$ for overall survival (OS), indicating a $35 \%$ reduction in risk of mortality in patients who underwent surgical excision of the primary tumor. Nevertheless, the analysis of 3 randomized clinical trials revealed a pooled hazard ratio of 0.85 ( $95 \% \mathrm{CI}, 0.59-1.21, P=0.359)$ for $O S$ in the surgical group. According to the meta-regression, the survival benefit was independent of age, tumor size, site of the metastases, and PR or HER-2 status, acceptance of systematic therapies and radiotherapy and inversely correlated with the ER+ status of the population included.

Conclusions: This is the first meta-analysis that includes both retrospective and prospective studies regarding the impact of surgery of the primary tumor on survival in stage IV breast cancer patients. According to the analytical results, we do not recommend surgery of the primary tumor as routine therapy for stage IV breast cancer. However, for those who are supposed to have long life expectancy, physicians could discuss it with these patients, put forward surgery as a therapy choice and perform the operation under deliberation. 


\section{INTRODUCTION}

Breast cancer is the second common cancer in the world, and by far, the most frequent cancer among women with an estimated 1.67 million new cancer cases diagnosed in 2012 (25\% of all cancers) [1]. In the United States and Western Europe, approximately 5\% of women with primary breast cancer present de novo stage IV breast cancer [2]. The mainstream treatments in such advanced disease are systematic therapies including chemotherapy, endocrine therapy and target therapy. The surgery of the primary tumor is usually applied to obtain local control, alleviate cancer-related symptoms and meet the patients' desire. However, there are some hypotheses suggesting that removal of the primary tumor would help obtain control of the disease and reduce the distant spread of tumor cells. One hypothesis is the "self-seed" model. In this model, the primary tumor acts as a source of continued seeding of distant metastatic sites, which could "self-seed" and circulate back to the primary tumor, accelerating growth and angiogenesis through cytokine action [3]. The possibility that removal of the primary tumor may restore immunocompetence is also suggested by an investigation using a mouse model, showing that when compared with healthy mice, those with metastatic disease had recovery of antigenspecific antibody responses and T-cell responses to foreign antigens after removal of the primary tumor [4]. Besides, a study by Campbell et al shows both CD4-positive and CD8-positive T-cell subsets producing type 1 (IL-2, IFN- $\gamma$ or TNF- $\alpha$ ) and type 2 (IL-4) cytokines were significantly reduced in patients with breast cancer, and they also observed a correlation between number of micrometastases in the bone marrow and $\mathrm{T}$ cell responsiveness [5]. Based on these hypotheses, surgery of the primary tumor is likely to control the disease and further improve the survival of stage IV breast cancer patients.

Besides, "low-burden" stage IV disease is increasingly identified with sensitive imaging modalities such as PET/CT. Together with the application of modern systematic therapies such as trastuzumab, survival of stage IV patients seems to be improving [6]. The removal of the primary tumor has already been shown to improve survival in other metastatic disease such as melanoma [7], renal cell carcinoma [8], colorectal cancer [9] and gastric cancer [10]. Treatments for stage IV breast cancer patients should also be re-examined.

There are already some retrospective studies and randomized clinical trials evaluating survival benefits from excision of the primary tumor in stage IV breast cancer, but the results are ambiguous and the role of surgery remains unclear. These controversies compelled us to perform a systematic review and meta-analysis to further explore it. A meta-regression weighted for age, visceral or bone disease, rate of radiotherapy, systematic therapies offered, tumor size, ER status and HER-2 status was also performed.

\section{MATERIALS AND METHODS}

\section{Search methods for the identification of eligible studies}

A search of PubMed, OVID, ASCO symposium documents, ESMO symposium documents, and SABCS symposium documents was performed using the following keywords in the searching algorithm: Stage IV OR metastatic AND Breast Cancer AND Surgery OR Surgical Excision. We set English language as a restriction. The latest search was done on August 15, 2016. Two authors $(\mathrm{Lu} \mathrm{S}$ and $\mathrm{Wu} \mathrm{J}$ ) independently examined the title and abstract citations. All relevant texts, tables, and figures were reviewed for data extraction.

\section{Inclusion and exclusion criteria}

A prospective clinical trial or retrospective study of more than 50 patients with stage IV breast cancer was included if it compared the overall survival (OS) between the patients who underwent surgical excision of the primary tumor and patients who didn't. It was imperative that all patients were staged according to the TNM or AJCC Cancer Staging Manual [11] and the hazard ratios (HRs) for OS should be reported. Type of surgery could be either conservative (lumpectomy or tumorectomy) or demolitive (mastectomy) and could be associated with axillary node dissection (or sentinel node biopsy) or not. Studies were excluded if the survival data were incomplete, or have repeating datasets but less detailed analysis compared with other reports. Reviews, case reports, letters and commentaries were excluded.

\section{Data extraction and management}

Data were extracted by the authors independently using the following items: characteristics of included studies (author's name, journal, year of publication), baseline characteristics of included patients (sourcing of patients, median age, histology, ER status, PR status, HER-2 status, metastatic sites, number of metastases, nodal status and type of surgery), and the survival data. The Guidelines in the Cochrane Handbook for Systematic Review of Interventions [12] were consulted from the methods to the presentation of results to the discussion of this meta-analysis.

\section{Statistical analysis}

Hazard Ratios (HRs) and their 95\% confidential intervals (95\% CIs) for OS, PFS, and TTP as benefit of surgery with or without other treatment modalities were retrieved from each study. Meta-analyses of HRs were performed with both fixed-effect and random-effect models. Statistical heterogeneity among the included 
studies was assessed using Cochran's $Q$ test, and a $\mathrm{X}^{2}$ test and $\mathrm{I}^{2}$ statistic test were used to quantify the inconsistency. The assumption of homogeneity was considered invalid for $P<0.1$. We took the random-effects model to calculate the pooled HR if the $\mathrm{X}^{2}$ test for heterogeneity showed $P$ $<0.01$ or the $\mathrm{I}^{2}$ test showed an index of more than $50 \%$, otherwise fixed-effects models were adopted.

Meta-regression analysis was performed to balance the results for specific covariates such as ER status, PR status and HER-2 status, receipt of systematic therapies (including chemotherapy, hormonal therapy and antiHER-2 therapy) mastectomy rate, margin status, use of radiotherapy (either to the primary tumor or the metastatic sites), performance status, median age, number of metastatic sites ( 1 vs $>1$ ), and type of metastases (visceral vs bone/soft tissue metastasis), whichever was available.

Finally, potential publication biases were evaluated with Begg's funnel plots for OS and subsequently with Begg's tests. A two-tailed $P$ value of $<0.05$ was considered statistically significant. Results of the metaanalyses were reported as a classical forest plot or data tables. Statistical analyses were performed using STATA version 12.0 and SPSS version 21.0.

\section{RESULTS}

A total of 237 articles were reviewed and 49 articles initially met the inclusion criteria, then 27 articles were excluded due to lack of HRs for OS in the multivariate analysis, not written in English, incomplete data sets or repeated datasets (Figure 1). Finally, 19 retrospective cohort studies [13-31] and 3 randomized clinical trials met the full inclusion criteria and were included in this metaanalysis [32, 33] (Supplementary Table 1).

\section{Patient and tumor characteristics}

A total of 67682 patients were included in the 19 retrospective studies and $46.4 \%$ of them were treated with surgery. Seven hundred and fourteen patients were included in the 3 randomized clinical trials with $49.0 \%$ undergoing surgery.

Data of surgery type were available in 16 studies; $14122(62.2 \%)$ patients underwent a mastectomy, while $8570(37.8 \%)$ were treated with breast-conserving procedures. Patients undergoing surgery were younger in all studies except the study by Dominici [17]. As for the tumor size, $65.4 \%$ of the patients in the surgical group had a tumor that was T2 or smaller compared with $54.0 \%$ in the nonsurgical group $(P<0.001)$. In the surgical group, 8.8\% patients had low-grade tumors, $32.7 \%$ had moderate-grade tumors and $58.5 \%$ had high-grade tumors, compared with $6.5 \%, 36.3 \%$ and $57.1 \%$ respectively in the non-surgery group. $69.6 \%$ of the surgical group was ER positive compared with $72 \%$ of the nonsurgical group $(P<0.001)$. There was no significant difference of PR status $(56.0 \%$ in surgical group versus $56.5 \%$ in nonsurgical group, $P=$ 0.473 ) and HER-2 status (36.9\% in surgical group versus $34.4 \%$ in nonsurgical group, $P=0.427$ ) between the two groups. Furthermore, patients in the surgical group had fewer metastases than their counterparts in the analysis of retrospective studies. ( $73.7 \%$ patients in the surgical group had metastasis in only one location versus $55.6 \%$ in the nonsurgical group $(P<0.001)$. Fewer patients in the surgical group had visceral metastasis $(52.8 \%$ versus $56.7 \%, P=0.023$ ) and the proportion of patients with bone metastasis is higher in the surgery group than in the nonsurgery group $(44.5 \%$ versus $40.8 \%, P=0.034)$.

In the randomized clinical trials, patients undergoing surgery had larger tumors $(3.8 \mathrm{~cm}$ versus $3.6 \mathrm{~cm}, P=0.01)$ and were more likely to have single organ metastasis $(P=0.001)$ in the TBCRC 013 clinical trial [34], whereas baseline demographic and disease characteristics were well balanced between groups in the other two clinical trials $[32,33,35]$.

\section{Primary endpoint (overall survival)}

The HRs for OS and standard errors for the estimated HRs were reported or extrapolated from all studies. A random-effects model was adapted to calculate the pooled HR of surgery for OS in the retrospective studies, which was 0.65 with a $95 \%$ CI of 0.6-0.71, confirming the assumption that surgery is beneficial in terms of reducing the risk of mortality by $35 \%$ (Figure 2 ). As for the randomized clinical trials, the pooled HR for OS was 0.85 with a $95 \% \mathrm{CI}$ of $0.59-1.21(P=0.359)$ (Figure 3 ).

The funnel plot for risk of bias in OS in the retrospective studies revealed that all studies, with the exceptions of Dominici, Rashaan and Shien et al [17], fell within the $95 \% \mathrm{CI}$, and were relatively symmetrically distributed (Figure 4). Evidence of publication bias was not revealed in the present analysis (Begg's test, $P=0.363$ ).

\section{Secondary endpoints}

Only three trials among those analyzed reported data about PFS/TTP. Hazard et al. reported a significant HR of 0.493 (for time to first progression for resected patients in multivariate analysis, $P=0.015)$. Lang et al. reported a benefit for surgery in PFS with an HR of $0.40(P<$ $0.0001)$ from multivariate analysis. Fields et al. suggested in the multivariate analysis that there was no significant difference between the time to metastatic progression in surgical and non-surgical group $(\mathrm{HR}=1.0, P=0.378)$. A formal meta-analysis was not possible due to the limited data available.

\section{Meta-regression analysis}

A meta-regression was performed to explore whether the HR for OS is affected by some other explanatory 
variables mentioned above. An inverse correlation of HR for OS and ER positive status was discovered $(P=0.03)$. A conversely positive association between OS and surgery of the primary tumor remained significantly independent of number of sites of disease, rate of bone or visceral metastasis, type of surgery, margin status, and median age.

\section{DISCUSSION}

The standard treatments for patients with stage IV breast cancer are systematic therapies, and surgical excision of the primary tumor is usually applied to palliate symptoms rather than to cure. All of the previous meta-

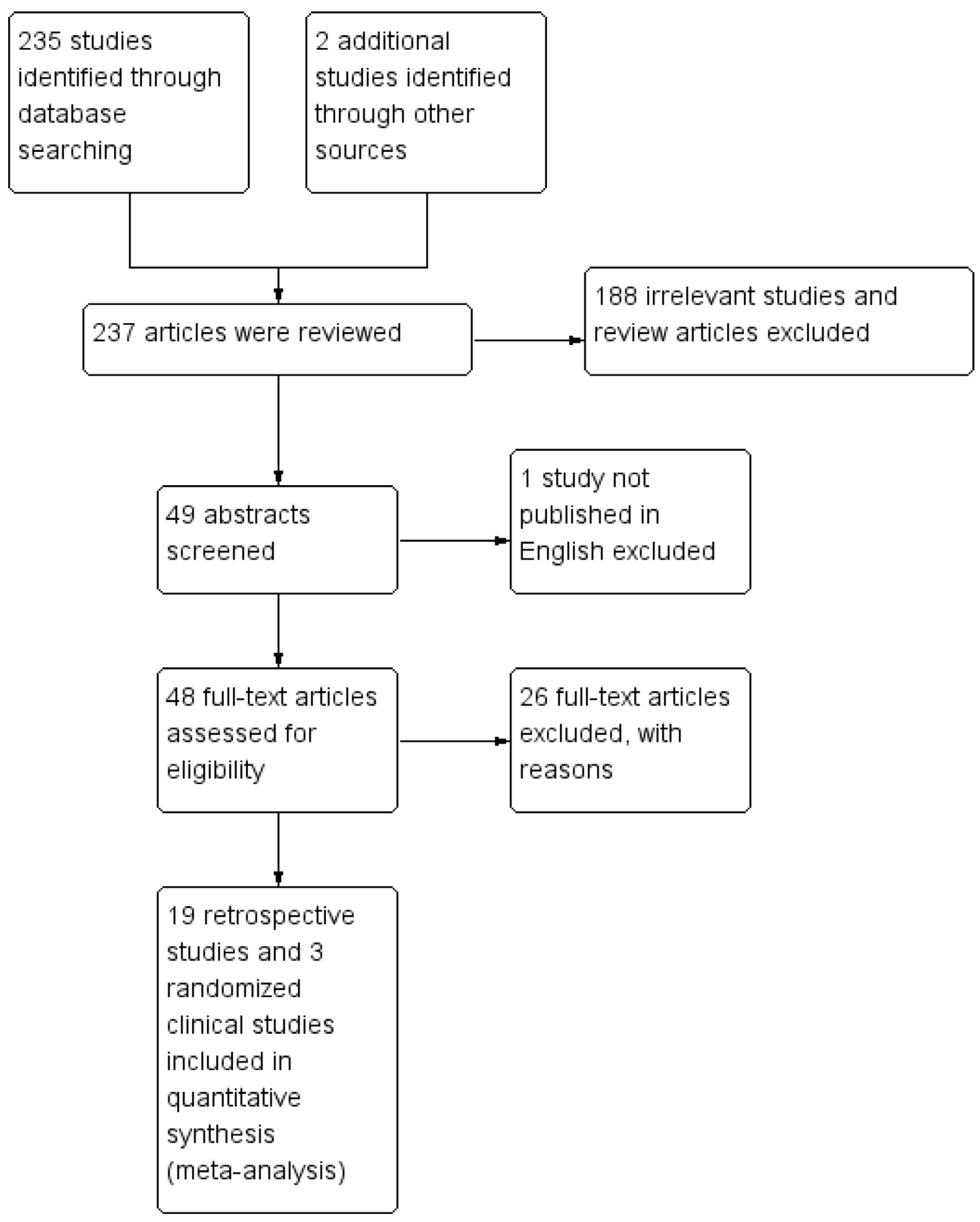

Figure 1: Consort flow of studies selected for meta-analysis comparing surgery versus no surgery of the primary tumor in the setting of stage IV disease. 
analysis and most of the regarding retrospective studies suggest that it is beneficial to perform an operation of the primary tumor for stage IV breast cancer patients. And with the emergency of the "self-seed" and "immunocompetence restore" model, the value of surgery of the primary tumor in stage IV breast cancer becomes the stuff of increasingly fierce debate.

This is the first meta-analysis studying the impact of surgery of the primary tumor on the survival of stage IV breast cancer patients that included both retrospective and prospective studies. Random-effects models were adopted to calculate the pooled HR of surgery for OS, which was 0.65 with a $95 \%$ CI of $0.6-0.71$ in the retrospective studies, indicating a $35 \%$ reduction in risk of mortality for patients undergoing surgery, and 0.85 with a $95 \%$ CI of $0.59-1.21$ in the randomized clinical trials, showing no statistically significant difference between the two groups.

Although the statistical result of the retrospective studies strongly suggests that surgical excision of the primary tumor in patients with stage IV breast cancer is beneficial in terms of survival, our analysis shows a large extent of selection bias in these studies. In those retrospective studies, women who received surgery tended to be younger, have smaller tumors, fewer comorbidities, lower burden of metastatic disease, less likely to have visceral metastases, and more likely to have access to better care. Differences between studies regarding inclusion criteria and study designs should not be neglected either. Furthermore, the retrospective studies covered the period 1962-2011 but we've made great progress in systematic therapy these years. When taking the results of the randomized clinical trials and the levels of evidence into account, we do not recommend surgery of the primary tumor as routine therapy for stage IV breast cancer patients.

Despite issues above, patients with good profile may gain longer survival, and they are liable to greater risk of losing local control and reduced quality of life over time. The study by Shien et al [30] also showed that patients with favorable profiles seemed to have the most benefit from surgery. What's more, according to our analysis, ER+ status is a positive predictor for OS of patients with stage IV breast cancer. Therefore, for these patients, especially hormonal receptor positive patients, surgery of the primary

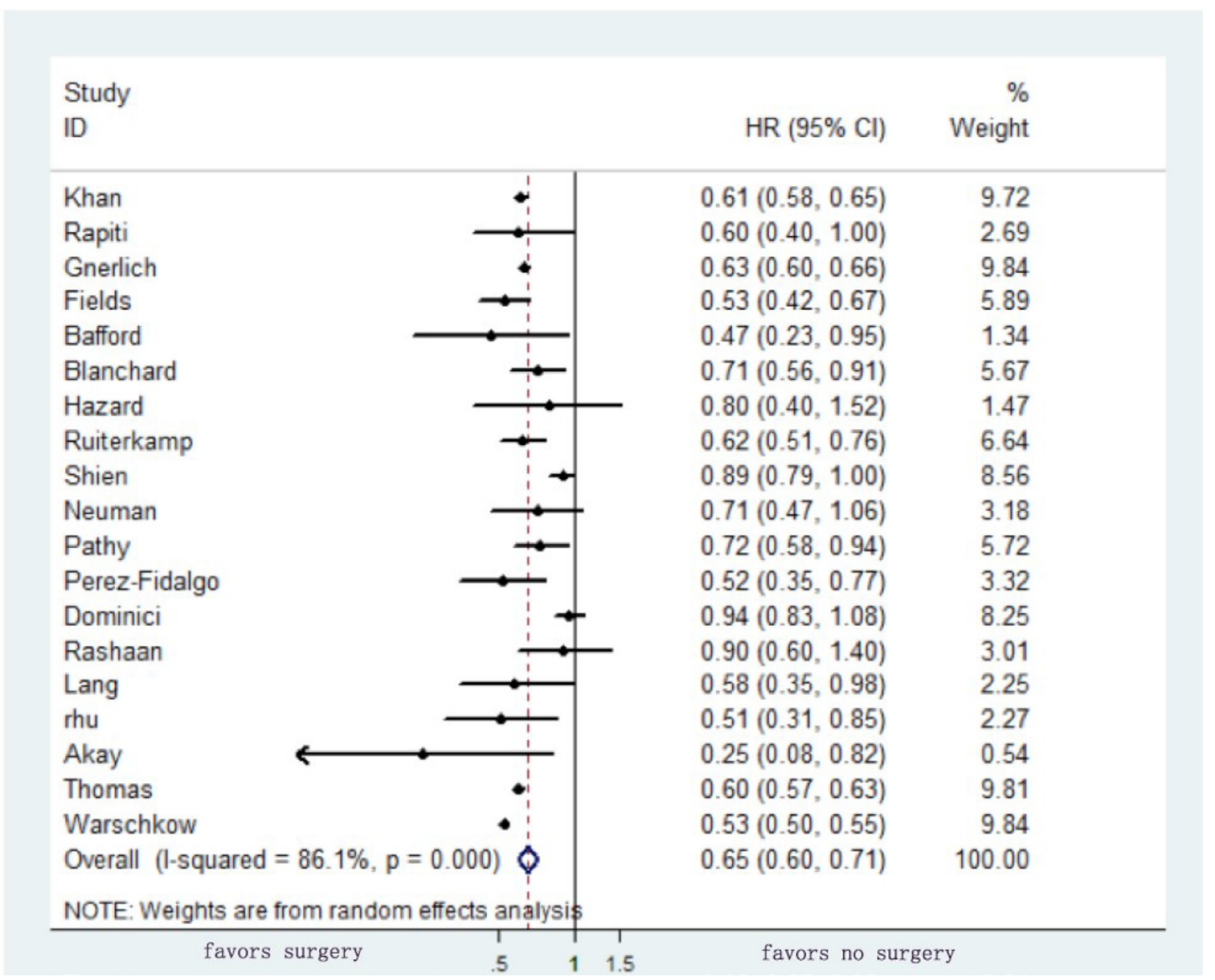

Figure 2: Pooled analysis of hazard ratio for overall survival of surgery versus no surgery of the primary tumor in patients with stage IV breast cancer. 


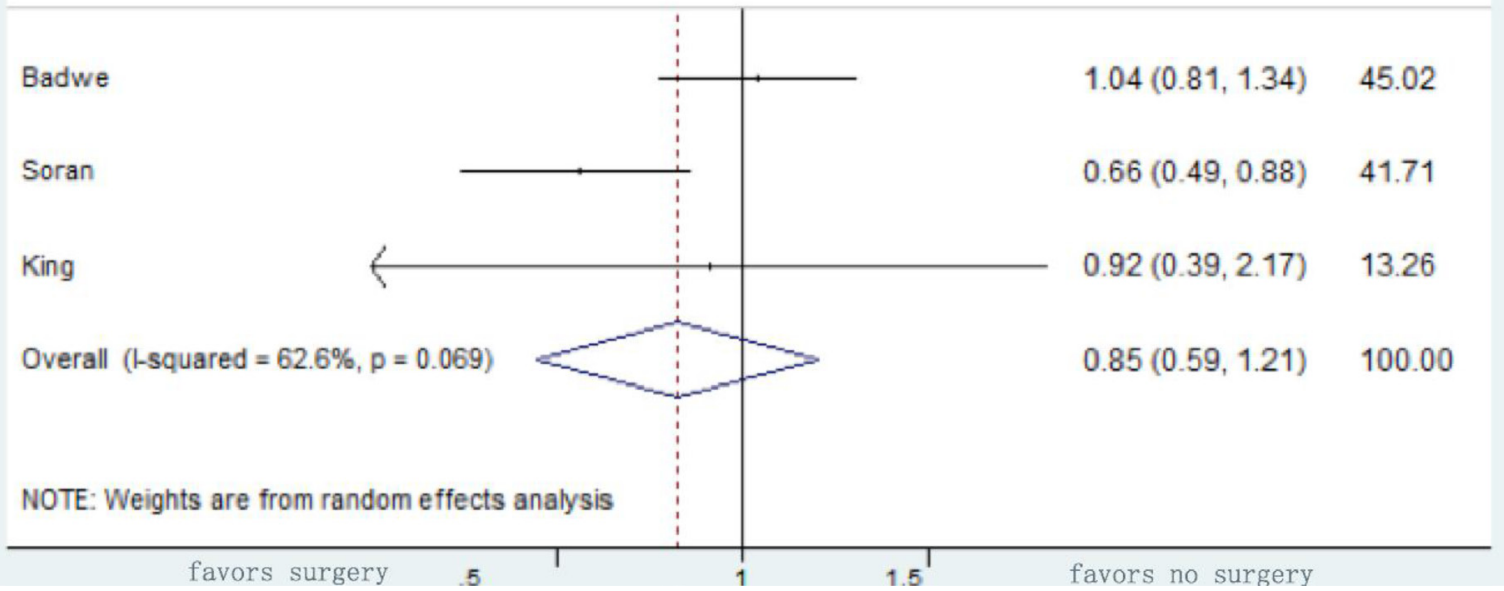

Figure 3: Forrest box-plot of survival meta-analysis of the randomized clinical trials comparing surgical excision of the primary tumor with no surgery for stage IV breast cancer patients.

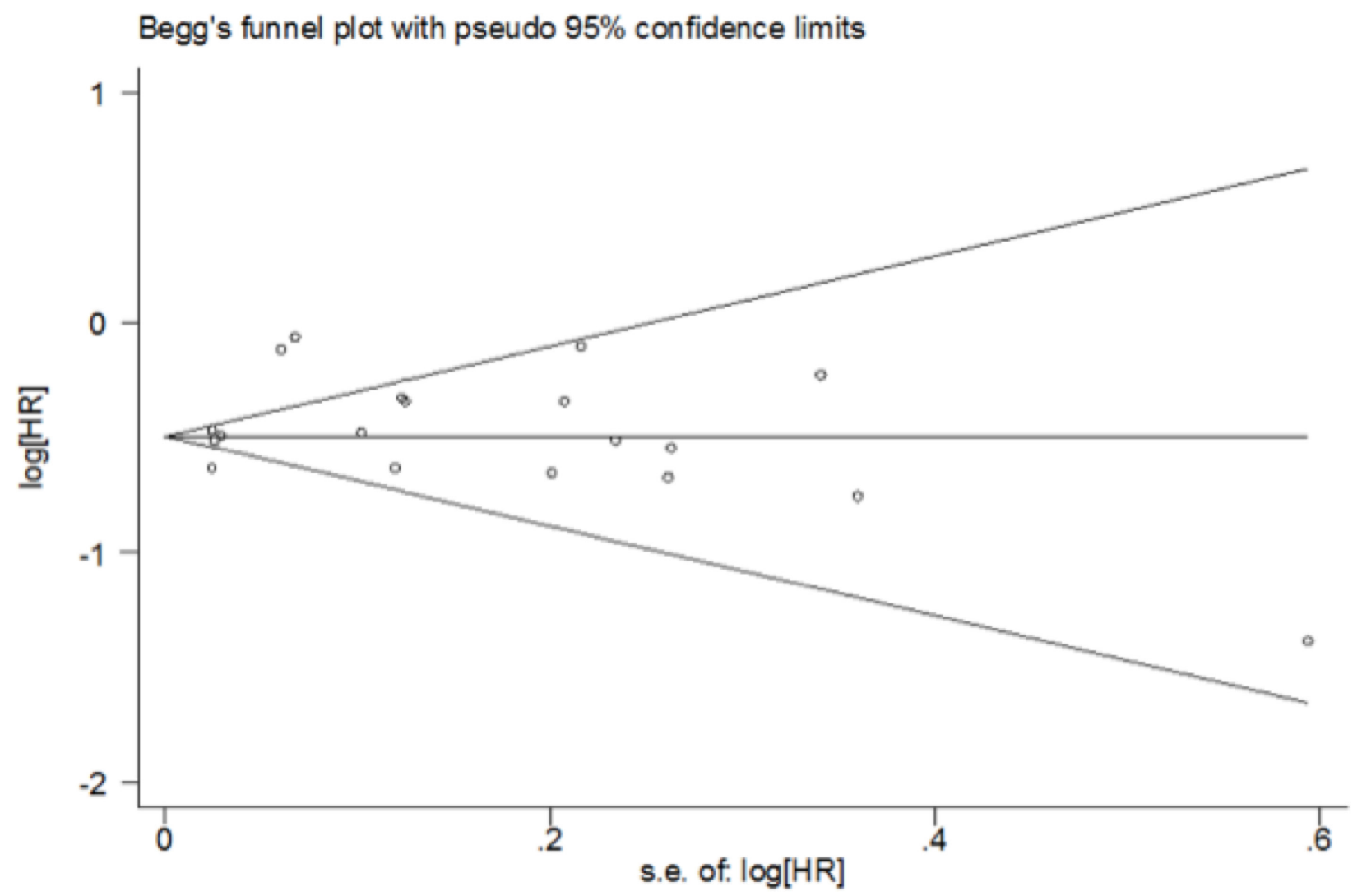

Figure 4: Funnel plot for overall survival meta-analysis. All previous studies, with the exception of the studies by Dominici, Rashaan, and Shien et al, were within the $95 \%$ confidence intervals and were relatively symmetrically placed. 
tumor may be of benefit in preventing local progression and even prolonging their survival. In clinical practice, physicians could discuss it with this kind of patients, put forward surgery as a therapy choice and perform the operation under deliberation.

There are also some limitations to this meta-analysis and its conclusions. This meta-analysis includes only three randomized clinical trials and there are also certain disparities in the design of these clinical trials. For example, only patients who had good response to the previous systematic therapy could get surgery in the TBCRC 013 trial [34], which weakens the stringency of this conclusion. And the final results of two of them are not fully exposed.

With the evolvement of adjuvant therapies and the paradigm shift of viewing stage IV diseases as chronic disease to be managed rather than a terminal event, the role of surgery will still be evolving, and we're looking forward to the disclosure of the other randomized clinical trials to help us to see it clearly.

\section{ACKNOWLEDGMENTS AND FUNDING}

This study was funded by National Natural Science Foundation of China 81572581 and Shanghai Science and Technology Committee project 16411966900 . The funders had no role in study design, data collection and analysis, decision to publish, or preparation of the manuscript.

\section{CONFLICTS OF INTEREST} declare.

None of the authors has a conflicts of interest to

\section{REFERENCES}

1. GLOBOCAN2012. Accessed August 3rd. 2016; Available from: http://globocan.iarc.fr/Pages/fact_sheets_cancer.aspx.

2. Siegel R, Naishadham D, Jemal A. Cancer statistics, 2013. CA Cancer J Clin. 2013; 63:11-30. https://doi.org/10.3322/ caac. 21166.

3. Kim MY, Oskarsson T, Acharyya S, Nguyen DX, Zhang XH, Norton L, Massagué J. Tumor self-seeding by circulating cancer cells. Cell. 2009; 139:1315-26. https:// doi.org/10.1016/j.cell.2009.11.025.

4. Danna EA, Sinha P, Gilbert M, Clements VK, Pulaski BA, Ostrand-Rosenberg S. Surgical removal of primary tumor reverses tumor-induced immunosuppression despite the presence of metastatic disease. Cancer Res. 2004; 64:220511. https://doi.org/10.1158/0008-5472.CAN-03-2646.

5. Campbell MJ, Scott J, Maecker HT, Park JW, Esserman LJ. Immune dysfunction and micrometastases in women with breast cancer. Breast Cancer Res Treat. 2005; 91:163-71. https://doi.org/10.1007/s10549-004-7048-0.

6. Andre F, Slimane K, Bachelot T, Dunant A, Namer M, Barrelier A, Kabbaj O, Spano JP, Marsiglia H, Rouzier R,
Delaloge S, Spielmann M. Breast cancer with synchronous metastases: trends in survival during a 14-year period. J Clin Oncol. 2004; 22:3302-08. https://doi.org/10.1200/ JCO.2004.08.095.

7. Essner R, Lee JH, Wanek LA, Itakura H, Morton DL. Contemporary surgical treatment of advanced-stage melanoma. Arch Surg. 2004; 139:961-66. https://doi. org/10.1001/archsurg.139.9.961.

8. Flanigan RC, Salmon SE, Blumenstein BA, Bearman SI, Roy V, McGrath PC, Caton JR Jr, Munshi N, Crawford ED. Nephrectomy followed by interferon alfa- $2 \mathrm{~b}$ compared with interferon alfa-2b alone for metastatic renal-cell cancer. $\mathrm{N}$ Engl J Med. 2001; 345:1655-59. https://doi.org/10.1056/ NEJMoa003013.

9. Rosen SA, Buell JF, Yoshida A, Kazsuba S, Hurst R, Michelassi F, Millis JM, Posner MC. Initial presentation with stage IV colorectal cancer: how aggressive should we be? Arch Surg. 2000; 135:530-34. https://doi.org/10.1001/ archsurg.135.5.530.

10. Hallissey MT, Allum WH, Roginski C, Fielding JW. Palliative surgery for gastric cancer. Cancer. 1988; 62:440 44.

11. Greene Fl PD. Fleming Id, AJCC Cancer Staging Manual. 6th ed. New York: Springer. Singletary SE, Allred C, Ashley P, Bassett LW, Berry D, Bland KI, Borgen PI, Clark GM, Edge SB, Hayes DF, Hughes LL, Hutter RV, Morrow M, et al. Surg Clin North Am. 2003; 83:803-19.

12. Higgins Jpt GS. Cochrane Handbook for Systematic Reviews of Interventions Version 5.1.0. The Cochrane Collaboration; 2011.

13. Akay CL, Ueno NT, Chisholm GB, Hortobagyi GN, Woodward WA, Alvarez RH, Bedrosian I, Kuerer HM, Hunt KK, Huo L, Babiera GV. Primary tumor resection as a component of multimodality treatment may improve local control and survival in patients with stage IV inflammatory breast cancer. Cancer. 2014; 120:1319-28. https://doi. org/10.1002/cncr.28550.

14. Bafford AC, Burstein HJ, Barkley CR, Smith BL, Lipsitz S, Iglehart JD, Winer EP, Golshan M. Breast surgery in stage IV breast cancer: impact of staging and patient selection on overall survival. Breast Cancer Res Treat. 2009; 115:7-12. https://doi.org/10.1007/s10549-008-0101-7.

15. Blanchard DK, Shetty PB, Hilsenbeck SG, Elledge RM. Association of surgery with improved survival in stage IV breast cancer patients. Ann Surg. 2008; 247:732-38. https:// doi.org/10.1097/SLA.0b013e3181656d32.

16. Cady B, Nathan NR, Michaelson JS, Golshan M, Smith BL. Matched pair analyses of stage IV breast cancer with or without resection of primary breast site. Ann Surg Oncol. 2008; 15:3384-95. https://doi.org/10.1245/s10434-008-0085-x.

17. Dominici L, Najita J, Hughes M, Niland J, Marcom P, Wong YN, Carter B, Javid S, Edge S, Burstein H, Golshan M. Surgery of the primary tumor does not improve survival in stage IV breast cancer. Breast Cancer Res Treat. 2011; 129:459-65. https://doi.org/10.1007/s10549-011-1648-2. 
18. Fields RC, Jeffe DB, Trinkaus K, Zhang Q, Arthur C, Aft R, Dietz JR, Eberlein TJ, Gillanders WE, Margenthaler JA. Surgical resection of the primary tumor is associated with increased long-term survival in patients with stage IV breast cancer after controlling for site of metastasis. Ann Surg Oncol. 2007; 14:3345-51. https://doi.org/10.1245/s10434007-9527-0.

19. Gnerlich J, Jeffe DB, Deshpande AD, Beers C, Zander C, Margenthaler JA. Surgical removal of the primary tumor increases overall survival in patients with metastatic breast cancer: analysis of the 1988-2003 SEER data. Ann Surg Oncol. 2007; 14:2187-94. https://doi.org/10.1245/s10434007-9438-0.

20. Hazard HW, Gorla SR, Scholtens D, Kiel K, Gradishar WJ, Khan SA. Surgical resection of the primary tumor, chest wall control, and survival in women with metastatic breast cancer. Cancer. 2008; 113:2011-19. https://doi.org/10.1002/ cncr.23870.

21. Khan SA, Stewart AK, Morrow M. Does aggressive local therapy improve survival in metastatic breast cancer? Surgery. 2002; 132:620-26. https://doi.org/10.1067/ msy.2002.127544.

22. Lang JE, Tereffe W, Mitchell MP, Rao R, Feng L, MericBernstam F, Bedrosian I, Kuerer HM, Hunt KK, Hortobagyi GN, Babiera GV. Primary tumor extirpation in breast cancer patients who present with stage IV disease is associated with improved survival. Ann Surg Oncol. 2013; 20:189399. https://doi.org/10.1245/s10434-012-2844-y.

23. Neuman HB, Morrogh M, Gonen M, Van Zee KJ, Morrow M, King TA. Stage IV breast cancer in the era of targeted therapy: does surgery of the primary tumor matter? Cancer. 2010; 116:1226-33. https://doi.org/10.1002/cncr.24873.

24. Pathy NB, Verkooijen HM, Taib NA, Hartman M, Yip CH. Impact of breast surgery on survival in women presenting with metastatic breast cancer. Br J Surg. 2011; 98:1566-72. https://doi.org/10.1002/bjs.7650.

25. Pérez-Fidalgo JA, Pimentel P, Caballero A, Bermejo B, Barrera JA, Burgues O, Martinez-Ruiz F, Chirivella I, Bosch A, Martínez-Agulló A, Lluch A. Removal of primary tumor improves survival in metastatic breast cancer. Does timing of surgery influence outcomes? Breast. 2011; 20:548-54. https://doi.org/10.1016/j.breast.2011.06.005.

26. Rapiti E, Verkooijen HM, Vlastos G, Fioretta G, NeyroudCaspar I, Sappino AP, Chappuis PO, Bouchardy C. Complete excision of primary breast tumor improves survival of patients with metastatic breast cancer at diagnosis. J Clin Oncol. 2006; 24:2743-49. https://doi. org/10.1200/JCO.2005.04.2226.

27. Rashaan ZM, Bastiaannet E, Portielje JE, van de Water W, van der Velde S, Ernst MF, van de Velde CJ, Liefers
GJ. Surgery in metastatic breast cancer: patients with a favorable profile seem to have the most benefit from surgery. Eur J Surg Oncol. 2012; 38:52-56. https://doi. org/10.1016/j.ejso.2011.10.004.

28. Rhu J, Lee SK, Kil WH, Lee JE, Nam SJ. Surgery of primary tumour has survival benefit in metastatic breast cancer with single-organ metastasis, especially bone. ANZ J Surg. 2015; 85:240-44. https://doi.org/10.1111/ans.12548.

29. Ruiterkamp J, Ernst MF, van de Poll-Franse LV, Bosscha K, Tjan-Heijnen VC, Voogd AC. Surgical resection of the primary tumour is associated with improved survival in patients with distant metastatic breast cancer at diagnosis. Eur J Surg Oncol. 2009; 35:1146-51. https://doi. org/10.1016/j.ejso.2009.03.012.

30. Shien T, Kinoshita T, Shimizu C, Hojo T, Taira N, Doihara $\mathrm{H}$, Akashi-Tanaka S. Primary tumor resection improves the survival of younger patients with metastatic breast cancer. Oncol Rep. 2009; 21:827-32. https://doi.org/10.3892/ or_00000291.

31. Warschkow R, Güller U, Tarantino I, Cerny T, Schmied BM, Thuerlimann B, Joerger M. Improved Survival After Primary Tumor Surgery in Metastatic Breast Cancer: A Propensity-adjusted, Population-based SEER Trend Analysis. Ann Surg. 2016; 263:1188-98. https://doi. org/10.1097/SLA.0000000000001302.

32. Badwe R, Hawaldar R, Nair N, Kaushik R, Parmar V, Siddique S, Budrukkar A, Mittra I, Gupta S. Locoregional treatment versus no treatment of the primary tumour in metastatic breast cancer: an open-label randomised controlled trial. Lancet Oncol. 2015; 16:1380-88. https:// doi.org/10.1016/S1470-2045(15)00135-7.

33. Soran A, Ozbas S, Kelsey SF, Gulluoglu BM. Randomized trial comparing locoregional resection of primary tumor with no surgery in stage IV breast cancer at the presentation (Protocol MF07-01): a study of Turkish Federation of the National Societies for Breast Diseases. Breast J. 2009; 15:399-403. https://doi.org/10.1111/j.15244741.2009.00744.x.

34. King TA, Lyman JP, Gonen M, Voci A, De Brot M, Boafo C, Sing AP, Hwang ES, Alvarado MD, Liu MC, Boughey JC, McGuire KP, Van Poznak CH, et al. A prospective analysis of surgery and survival in stage IV breast caner (TBCRC 013). 2016; Translational Breast Cancer Research Consortium: 2016 ASCO Annual Meeting.

35. Soran A, Ozbas S, Kelsey SF, Gulluoglu BM. Randomized trial comparing locoregional resection of primary tumor with no surgery in stage IV breast cancer at the presentation (Protocol MF07-01): a study of Turkish Federation of the National Societies for Breast Diseases. 2016: 2016 ASCO Annual Meeting. 